\title{
CD36 polymorphisms and the age of disease onset in patients with pathogenic variants within the mutation cluster region of APC
}

T Connor ${ }^{1}$, M McPhillipss², M Hipwell ${ }^{2}$, A Ziolkowski² ${ }^{2}$ C Oldmeadow ${ }^{3}$, M Clapham³ ${ }^{3}$ PG Pockney ${ }^{4}$, E Lis ${ }^{5,6}$, T Banasiewicz ${ }^{5}$, A Pławski, ${ }^{5,6}$ and RJ Scott ${ }^{1,2,7^{*}}$

\begin{abstract}
Background: Familial adenomatous polyposis (FAP) is an autosomal dominant condition that predisposes patients to colorectal cancer. FAP is the result of a loss of APC function due to germline pathogenic variants disrupting gene expression. Genotype-phenotype correlations are described for FAP. For example attenuated forms of the disease are associated with pathogenic variants at the $5^{\prime}$ and $3^{\prime}$ ends of APC whilst severe forms of the disease appear to be linked to variants occurring in the mutation cluster region (MCR) of the gene. Variants occurring in the MCR are phenotypically associated with hundreds to thousands of adenomas carpeting the colon and rectum and patients harbouring changes in this region have a high propensity to develop colorectal cancer. Not all patients who carry pathogenic variants in this region have severe disease which may be a result of environmental factors. Alternatively, phenotypic variation observed in these patients could be due to modifier genes that either promote or inhibit disease expression. Mouse models of FAP have provided several plausible candidate modifier genes, but very few of these have survived scrutiny. One such genetic modifier that appears to be associated with disease expression is CD36. We previously reported a weak association between a polymorphism in CD36 and a later age of disease onset on a relatively small FAP patient cohort.
\end{abstract}

Methods: In the current study, we enlarged the FAP cohort. 395 patients all carrying pathogenic variants in APC were tested against three CD36 Single Nucleotide Polymorphisms (SNP)s (rs1049673, rs1761667 rs1984112), to determine if any of them were associated with differences in the age of disease expression.

Results: Overall, there appeared to be a statistically significant difference in the age of disease onset between carriers of the variant rs 1984112 and wildtype. Furthermore, test equality of survivor functions for each SNP and mutation group suggested an interaction in the Log Rank, Wilcoxon, and Tarone-Ware methods for rs1049673, rs1761667, and rs1984112, thereby supporting the notion that CD36 modifies disease expression.

(Continued on next page)

\footnotetext{
* Correspondence: rodney.scott@newcastle.edu.au

'School of Biomedical Sciences, Faculty of Health, University of Newcastle, Callaghan Campus, NSW 2308 Newcastle, Australia

${ }^{2}$ Division of Molecular Medicine, NSW Health Pathology North, 2305 New Lambton, NSW, Australia

Full list of author information is available at the end of the article
}

(c) The Author(s). 2021 Open Access This article is licensed under a Creative Commons Attribution 4.0 International License, which permits use, sharing, adaptation, distribution and reproduction in any medium or format, as long as you give appropriate credit to the original author(s) and the source, provide a link to the Creative Commons licence, and indicate if changes were made. The images or other third party material in this article are included in the article's Creative Commons. licence, unless indicated otherwise in a credit line to the material. If material is not included in the article's Creative Commons licence and your intended use is not permitted by statutory regulation or exceeds the permitted use, you will need to obtain permission directly from the copyright holder. To view a copy of this licence, visit http://creativecommons.org/licenses/by/4.0/ The Creative Commons Public Domain Dedication waiver (http://creativecommons.org/publicdomain/zero/1.0/) applies to the data made available in this article, unless otherwise stated in a credit line to the data. 
(Continued from previous page)

Conclusions: This study supports and strengthens our previous findings concerning CD36 and an association with disease onset in FAP, AFAP and FAP-MCR affected individuals. Knowledge about the role CD36 in adenoma development may provide greater insight into the development of colorectal cancer.

Keywords: FAP, Disease phenotype, Polyposis, Modifier gene, CD36

\section{Background}

Familial adenomatous polyposis (FAP) is an autosomal dominantly inherited condition affecting between 1 in 7 , 000-22,000 people $[1,2]$. Approximately $20-30 \%$ of these patients will be considered de novo presentations and are likely to present with more advanced disease [3]. The clinical diagnosis of FAP is based on the presence of 100's to 1000's of colorectal adenomas. Adenoma development can be macroscopically observed in the colon and rectum by the first to second decades of life. Many patients will be asymptomatic and, if adenomas are not detected early and appropriate prophylactic measures taken, develop with almost certainty into colorectal cancer by the age of $50[4,5]$. Before identifying $A P C$, FAP was considered to be relatively restricted to colonic polyposis and or Gardner's syndrome, with or without the presence of congenital hypertrophy of the retinal pigment epithelium. After the identification of $A P C$, the phenotype expanded to include variant forms of the disease, which ranged from very mild disease (reduced expressivity) to allelic variants that did not display overt polyposis [6-11].

FAP results from the reduced or absent expression of adenomatous polyposis coli (APC) located on chromosome 5q21-22.2 [12]. Overall, there appears to be a genotype-phenotype correlation in patients with FAP (for review, see Nieuwenhuis and Vasen 2006 [13]), with severe disease being associated with variants occurring in the mutation cluster region (MCR) of $A P C$ [14] and attenuated FAP being linked to variants $5^{\prime}$ of codon 157 [15] and 3' of codon 1581 [16]. Notwithstanding, there are significant exceptions to the notion of a genotype/ phenotype correlation in FAP, which is more readily explained by other factors that impact adenoma multiplicity.

Mouse models of FAP have been used extensively to search for genetic modifiers of disease expression and multiple murine modifier genes have been reported [1721]. Thus far, modifiers of FAP have been difficult to associate with human disease, with some of the mouse model contenders showing no association in humans $[22,23]$. Recently, the Mom5 locus, which encompassed $C d 36$, was identified as a potential modifier of disease expression in a mouse model of FAP [24]. We have previously reported tentative evidence that polymorphisms in $C D 36$ influence the age at which polyposis expression occurs [25], based on a relatively small population of patients with confirmed $A P C$ pathogenic variants.

In this study, we present additional evidence that adds integrity to our previous report and confirms that variants in CD36 influence disease expression, especially in patients who carry germline variants in the mutation cluster region of $A P C$.

\section{Methods}

The patient cohort consisted of 432 individuals clinically diagnosed with familial adenomatous polyposis with a pathogenic germline variant in $A P C$. Those patients who did not have a genetic diagnosis of disease were excluded from the study. 278 patients were from Australia and 154 from Poland. All patients were ascertained between the years 1997-2017, and their status assigned at the time of diagnosis or their last clinical follow-up.

Patient groups were divided according to the pathogenic variant site within $A P C$, which correlated with phenotype: severe (FAP-MCR bounded by codons 1250 1513); attenuated (AFAP $=5$ 'end spanning exons 3 to 5 ; 3 'distal end and those in exon 9); and intermediate $(\mathrm{FAP}=$ the rest of the gene).

From the total cohort of 432 there were 37 patients that did not have enough DNA or there was missing clinical information to allow the sample to be included in the analysis. From the remaining 395 patients, there were 147 AFAP patients, 172 FAP patients and 76 patients who had pathogenic variants in the mutation cluster region (MCR-FAP) of $A P C$. The clinical data collected for this study included the age of diagnosis of polyposis. They were censored at the time of blood collection for the detection of pathogenic variants in APC.

The 395 FAP patient samples were used for genotyping three SNPs in CD36; rs1049673 (C> G), rs1761667 $(\mathrm{G}>\mathrm{A})$ and rs1984112 (A > G) located on chromosome 7q21.11. TaqMan SNP assays (Applied Biosystems) were used to identify the respective variants' presence or absence. SNP rs1049673 is located in exon 15 (3'-UTR), rs1761667 and rs1984112 are intronic variants flanking exon 1 A [26]. The SNP rs1761667 has been shown to reduce protein expression, while 3'-UTR variants often contain regulatory regions that post-translationally influence gene expression [27]. The 3 SNPs are in strong LD with three haplotype blocks described in the HapMap 
Table 1 Demographics and CD36 data obtained for combined cohort

\begin{tabular}{lll}
\hline & Category & Total $(\mathbf{N = 4 3 2 )}$ \\
\hline Age & mean (SD) & $29.4(15.3)$ \\
Mutation group & median (min, max) & $27(2,83)$ \\
& Other (FAP or AFAP) & $319(81 \%)$ \\
& APC MCR & $76(19 \%)$ \\
Polyps & Missing & 37 \\
rs1049673 & No & $88(20 \%)$ \\
& Yes & $339(78 \%)$ \\
Wildtype & $141(32 \%)$ \\
rs1761667 & Heterozygote & $184(43 \%)$ \\
& Variant & $82(19 \%)$ \\
Missing & $25(6 \%)$ \\
Wildtype & $95(22 \%)$ \\
& Heterozygote & $158(37 \%)$ \\
& Variant & $85(20 \%)$ \\
& Missing & $94(21 \%)$ \\
& Wildtype & $179(41 \%)$ \\
& Heterozygote & $168(39 \%)$ \\
& Variant & $57(13 \%)$ \\
& Missing & $28(6 \%)$ \\
\hline
\end{tabular}

database [28]. Allelic discrimination was undertaken according to the Taq- Man SNP Genotyping Assay Protocol, involving; $10 \mathrm{~min}$ at 95 degrees; 40 cycles of $15 \mathrm{~s}$ at 95 degrees; and $1 \mathrm{~min}$ at 60 degrees. For rs1049673, 407 genotypes were recorded; for rs1761667, 338 genotypes, and rs1984112, 404 were recorded. The reason for the failed genotyping was inadequate amounts of DNA.

Results were read using the ABI 7500 standard realtime PCR system (Applied Biosystems). Raw data were analysed using TaqMan Genotyper Software (Life Sciences, Foster City, CA). A Pearson's Chi-square test was used with $P$-values were calculated with degrees of freedom from the log-rank, Wilcoxon, and Tarone test, along with the number of subjects at risk to account the differing weights of each calculation. The SNPs were stratified by mutation group and type, a p-value from a joint test of the interaction term between the mutation group and type.
Statistical analysis was performed using Stata v14.0 (StataCorp LP, TX USA) and SAS v9.4 (SAS Institute, Cary, North Carolina, USA). The cohort of patients was divided into 3 patient groups, APC-MCR (76 patients), FAP (172 patients), and AFAP (147).

Pearson's Chi-square test was used to evaluate deviation from the expected Hardy-Weinberg equilibrium (HWE). Statistical analysis was performed using Stata 12.1 (StataCorp LP, TX USA). We applied Bonferroni correction for multiple testing, resulting in a corrected significance threshold of $p=0.0167$ (0.05 divided by the 3 SNPs tested). Due to the nature of the disease and the strong recommendation for prophylactic surgery, the diagnosis of polyposis was used as an endpoint for analysis. Variation in the age of polyposis diagnosis between each SNP; wildtype genotype (homozygous for wildtype allele), heterozygote, and variant genotype (homozygous for variant allele) and mutation group (based on mutation location as described above); was examined using Kaplan-Meier plots. Individuals free from polyposis were censored at their age, at last, follow up. Wilcoxon's (Breslow), Log-rank, and Tarone-Ware tests were used to examine the Kaplan-Meier plots' homogeneity. The logrank test is more sensitive to differences later in time due to equal weighting over the curve, where the Wilcoxon weights the early differences higher than the later differences using the number at risk in the weighting. The Tarone-ware test uses the square root of the number at risk in the weighting. All three tests were required to be significant for results to be considered reliable. Cox regression models were used to provide a formal Wald-test of interaction (global interaction test) between APC mutation groups and SNPs genotypes, taking into account family ID as a group variable.

\section{Results}

The total number of patients recruited into this study was 432 of which 37 could not be included due to either insufficient DNA or the absence of clinical information about the patient. The descriptive statistics outlining age, mutation group, adenomas, and SNPs tested within the population is presented in Table 1.

The first approach taken was to determine if there was any indication of a difference between the three groups

Table 2 Test equality of survivor functions for each SNP and mutation group, p-value's (Chi-squared test statistic, degrees of freedom)

\begin{tabular}{lllll}
\hline SNP & Log_Rank & Wilcoxon & Tarone & SNP/ Mutation group Interaction \\
\hline rs1049673 & $<.0001(32.89, \mathrm{df}=5)$ & $<.0001(30.73, \mathrm{df}=5)$ & $<.0001(32.11, \mathrm{df}=5)$ & 0.0528 \\
rs1761667 & $<.0001(26.20, \mathrm{df}=5)$ & $<.0001(25.66, \mathrm{df}=5)$ & $<.0001(26.46, \mathrm{df}=5)$ & 0.1917 \\
$\mathrm{rs1984112}$ & $<.0001(47.71, \mathrm{df}=5)$ & $<.0001(50.81, \mathrm{df}=5)$ & $<.0001(49.81, \mathrm{df}=5)$ & 0.0417 \\
\hline
\end{tabular}


a

\section{Kaplan Meier Analysis}
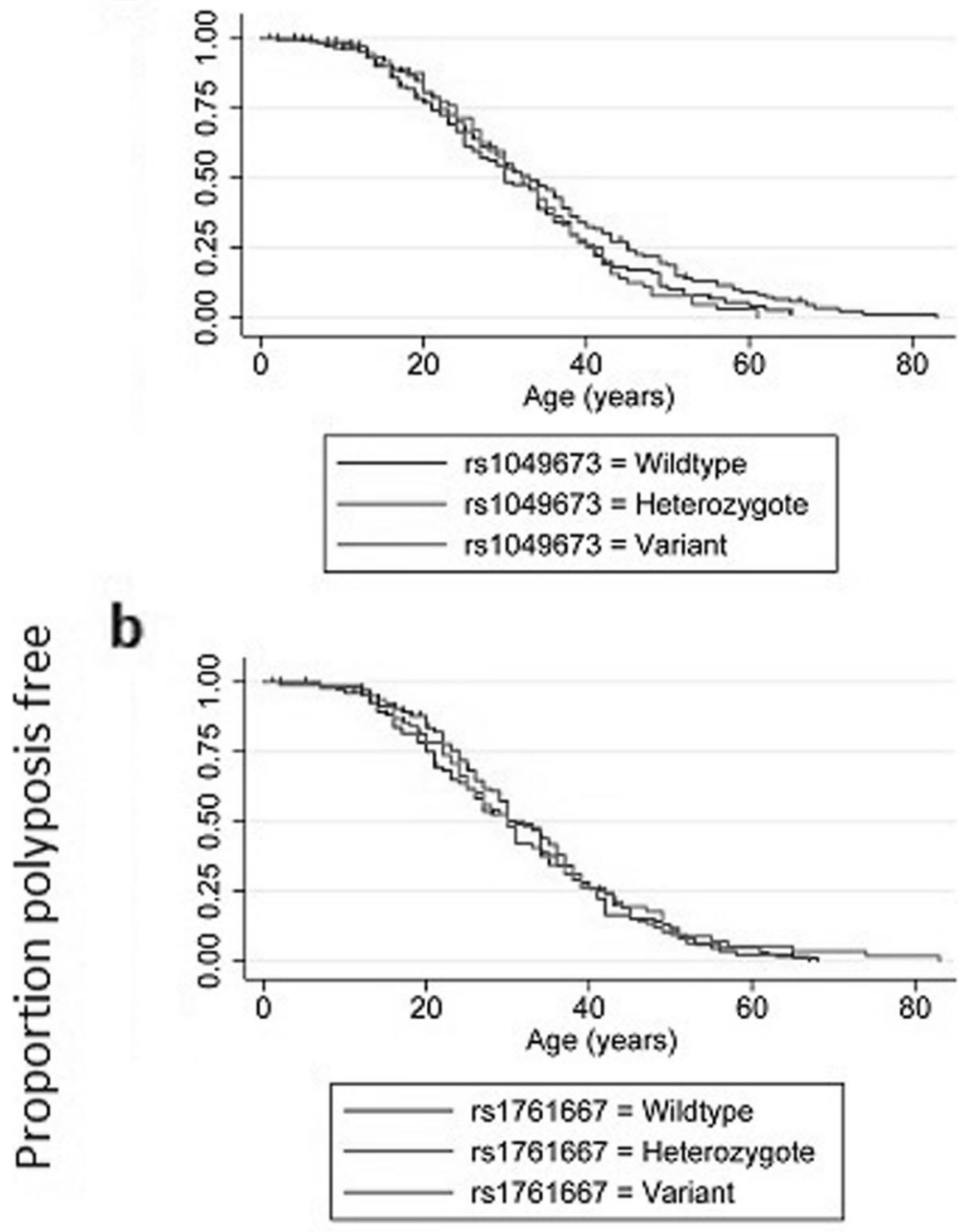

C

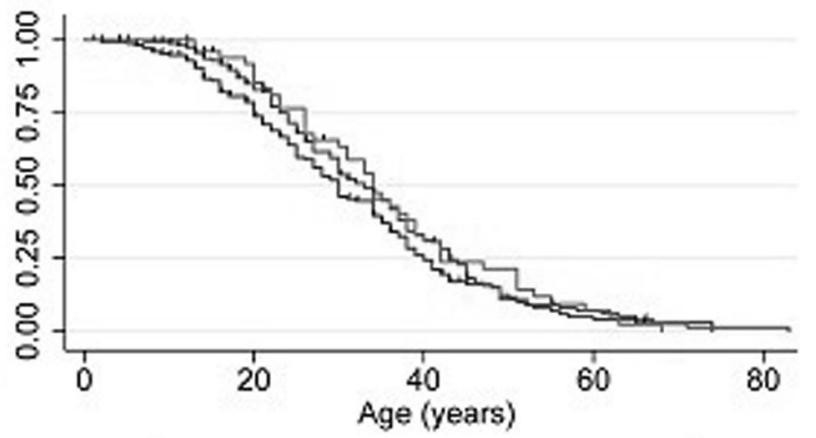

\section{rs1984112 = Wildtype \\ rs1984112 = Heterozygote rs1984112 = Variant}

Fig. 1 SNP distribution within the entire cohort of patients carrying deleterious APC variants. Overall rs1049673 and rs 176667 did not reveal any association with the age of disease presentation. For rs1984112 there appeared to be some evidence that the variant SNP was associated with a slightly later age of disease presentation compared to its wildtype counterpart 


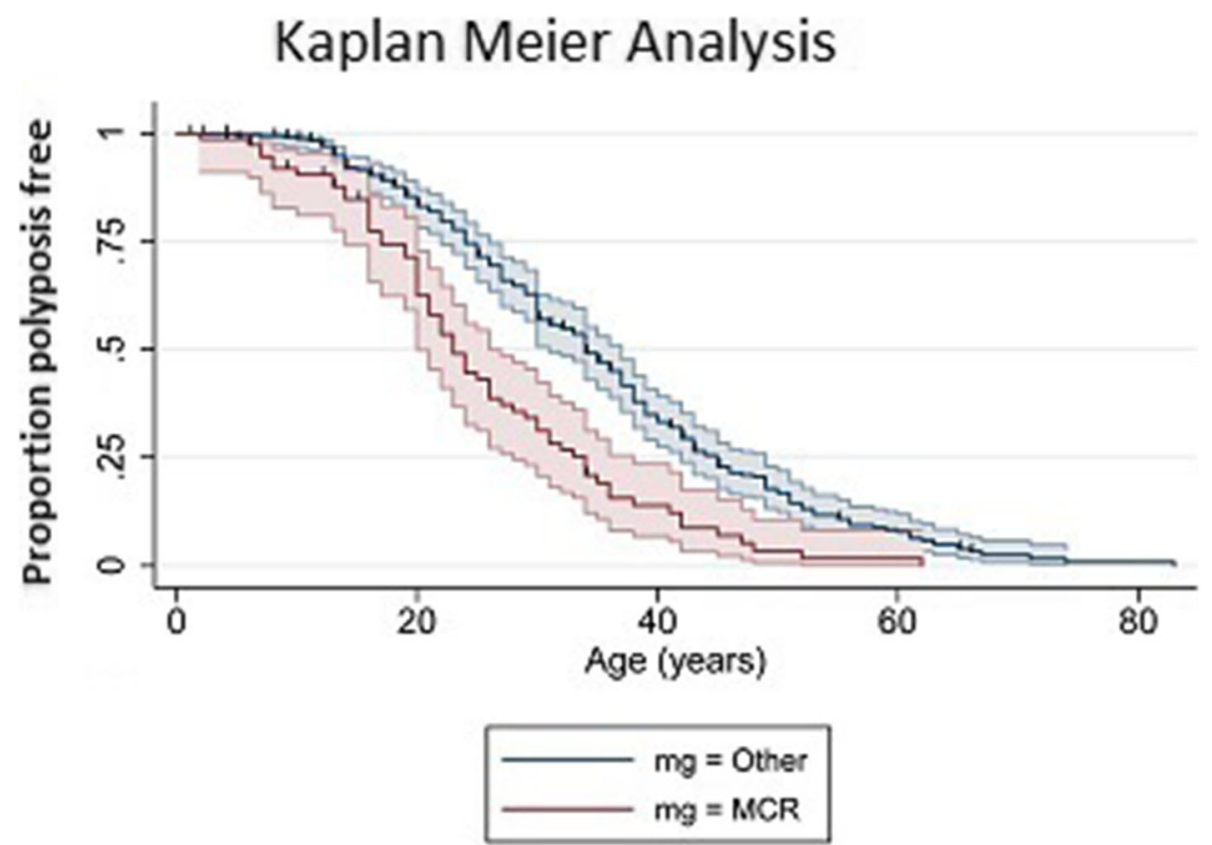

Fig. 2 Differences in the average age of disease presentation between patients with APC pathogenic variants bounded within the mutation cluster region (MCR) compared to patients whose germline pathogenic variants resided outside of the MCR

of patients and one or more of the CD36 SNPs under investigation, the results of which are presented in Table 2.

This table represents all three SNPs showing a statistically significant difference at $5 \%$ compared with Wildtype, Heterozygote, or variant mutation groups. For SNP rs1984112, the SNP/Mutation interaction is $p=0.04$ indicating a statistical difference between mutation interaction.

For rs1049673, there was no difference in the age of disease diagnosis if the patient was wildtype, heterozygous, or a homozygous variant for this SNP (Fig. 1a). Similarly, for rs1761667, no differences could be observed (Fig. 1b). No statistically significant result was revealed for rs1984112. Still, patients carrying only wildtype alleles did appear to present with the disease at a slightly younger age than heterozygote or homozygote variant carriers (Fig. 1c).

The potential difference between patients homozygous for rs1984112 suggested some effect of this variant on disease expression. Since an analysis of all FAP patients as a single group is not representative of individuals' phenotypic status, the patients were categorised into three groups based on the location of each patient's $A P C$ pathogenic variant and correlated disease severity. Patients carrying variants in those regions of $A P C$ associated with an attenuated form of the disease were classed as one group (AFAP), patients having pathogenic variants within the MCR were classed as the most severe group (MCR-FAP) and all other patients were considered as "standard" polyposis patients (FAP).

An analysis of the age of disease diagnosis was undertaken focussing on those patients who carried pathogenic $A P C$ variants in the MCR compared to all other patients (AFAP/FAP). The results revealed that the MCR-FAP group developed the disease approximately 10 years earlier than their AFAP/FAP counterparts (Fig. 2).

Examination of rs 1049673 revealed no influence of this SNP on the age of disease diagnosis for the MCR-FAP group or the remaining patients even though there remained a difference in the overall age of diagnosis between the MCR-FAP group and the FAP/AFAP group (see Fig. 3a). A similar result was observed for rs1761667 in that this SNP did not influence the age of disease diagnosis (Fig. 3b).

The three genotypes of rs1984112 were found to be similar in the AFAP/FAP group but significantly different in the MCR-FAP group of patients. Patients who were wildtype for the SNP were considerably younger at the time of diagnosis than patients who carried a wildtype allele and a variant allele or those who had two variant alleles (Fig. 3c). Using a dominant model, when combined, the heterozygote carriers and the homozygote variant carriers were significantly older at the time of their diagnosis compared to patients who were wildtype for this SNP (Fig. 4). When the variant allele's presence 

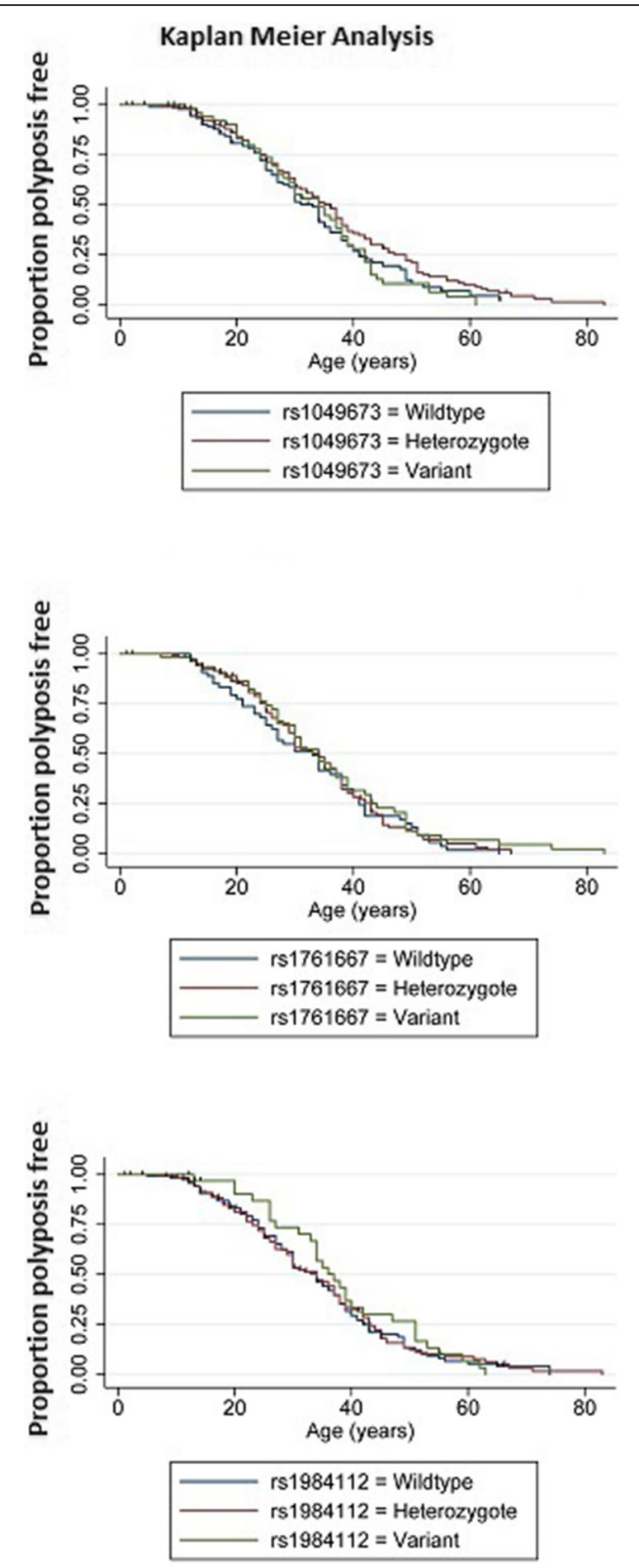

Fig. 3 Kaplan Meier analysis of patients carrying pathogenic variants outside of the MCR. Overall, the results were similar for rs 1049673 and rs176667 compared to the overall results presented in Fig. 1. For rs1984112 there is some evidence that indicates homozygote variant carriers present with disease at older ages compared to their wildtype and heterozygous counterparts

was considered an autosomal dominant modifier, a significant difference between the ages of polyposis presentation was observed, indicating the modifying effects of CD36 resulted in a later age of disease presentation within the MCR-FAP group.

Given the phenotypic heterogeneity in the AFAP group, a comparison between this group and the FAP was undertaken to consider the rs1049673, rs1761667, and rs1984112. No statistical differences in the ages of disease presentations were observed between the AFAP and FAP groups for any SNPs under investigation (data not shown).

Since AFAP has a much milder disease course than FAP, we re-analysed the data focussing on only the MCR-FAP patients and comparing them to FAP patients or AFAP patients alone. Similarly, for rs1409673 and rs1761667, no differences were observed between the three groups (wildtype, heterozygote, and homozygote variant carriers). For rs1984112 wildtype carriers, a statistically significant difference was observed between the MCR-FAP group and the FAP group. When examining the differences between the MCR-FAP and the FAP group, the results indicated a difference in the age of disease onset of all MCR-FAP patients compared to the FAP group. The effect of rs1984112 on disease onset was statistically significantly different in the MCR-FAP group but not the FAP group. A similar finding was revealed when the MCR-FAP group was compared to the AFAP cohort.

\section{Discussion}

Disease expression in FAP is associated with the site of the pathogenic variant residing in APC. It has been extensively reported that a genotype-phenotype correlation exists, which is linked to the location of the pathogenic variant in $A P C$ and how this influences disease expression [29] via several different mechanisms [30]. Notwithstanding, the correlations that have been described represent approximations that cannot be used to accurately define or predict disease expression in any given patient [31]. An alternative and potentially complementary explanation for the diversity in disease expression observed in FAP is the influence of other factors that could either promote or inhibit disease expression. The presence of one or more modifier genes that influence 


\section{Kaplan Meier Analysis}

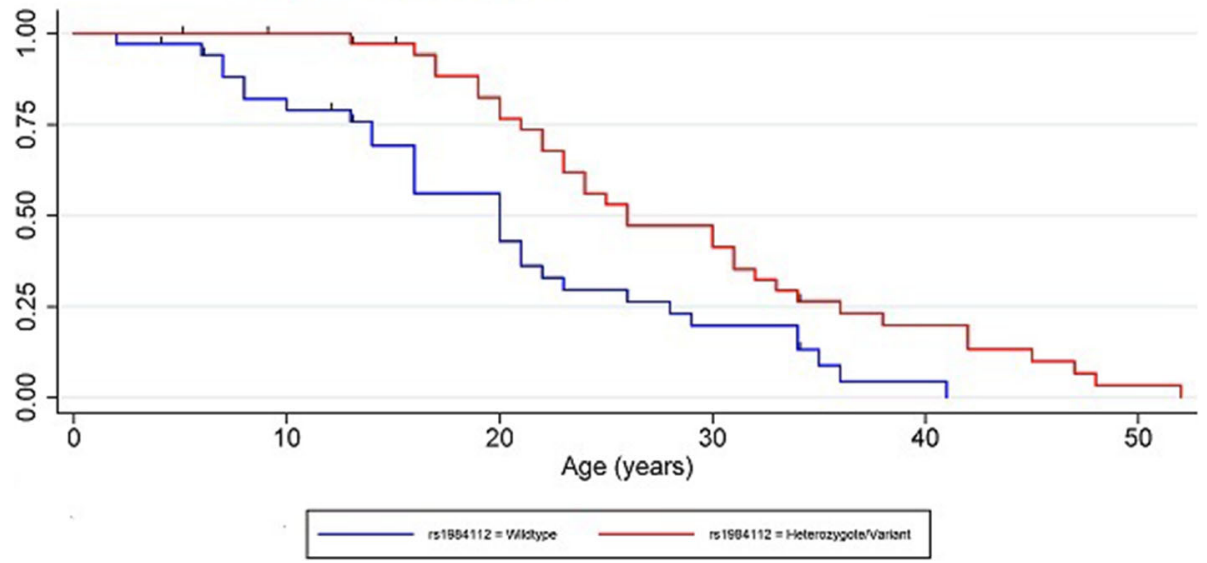

Fig. 4 Kaplan Meier analysis for rs1984112 modelling the variant allele as an autosomal dominant modifier. The difference is highly statistically significant for all aspects of the analysis

disease risk in FAP has been reported several times [32, 33], but none have been replicated, thereby casting doubt on their integrity.

Identifying genetic factors associated with phenotypic variability in FAP is the heterogeneity of disease expression related to the location of the causative APC pathogenic variant. In this study, we have based our associations on the genotype-phenotype correlations in APC, thereby circumventing the requirement of obtaining actual polyp counts in each patient and the necessity of identifying a large pool of patients all carrying the same pathogenic variant.

Searching for modifier genes in a rare human genetic disorder is challenging, and much focus has been placed on studies of mouse models of disease. The use of the Min mouse (and other mouse models of disease) has revealed several candidate modifier genes that appear to influence disease in the mouse. A relatively recent modifier of Fap, known as Mom-5, was reported in 2015 [24], which seemed to affect adenoma multiplicity. We have previously reported on the role of CD36 in a relatively small group of FAP patients, which revealed a potential association of the wildtype allele of rs1984112 with an earlier age of disease onset compared to heterozygous and homozygous variant carriers [25]. The link between colorectal cancer risk and CD36 has been explored in that variants in rs 1984112 have been associated with hypercholesterolemia [34], a known risk factor colorectal cancer [35].

The number of patients in the study by Holmes et al. [25] was too small to interrogate further the relationship between rs1984112 and patients diagnosed with AFAP, FAP, and MCR-FAP. In the current study, it became evident that rs1984112 did not influence the age of disease diagnosis in patients deemed to be AFAP or "standard" FAP. The absence of any effect of rs1984112 on these two groups of patients may be due to the variance in disease penetrance across the cohort [35]. The MCR-FAP group is considered the most severe group of patients with relatively consistent disease expression. It has been well recognised that disease penetrance is not uniform. Still, the MCR-FAP group tends to develop hundreds to thousands of adenomas, which confers a high risk of malignant transformation.

The finding that patients who are wild type for the CD36 polymorphism develop disease somewhere between 5 and 10 years before heterozygotes and homozygote variants is important since this information could be used if replicated to tailor when colectomy be considered. Since adenoma multiplicity is almost impossible to obtain, it is unknown if CD36 polymorphisms can be correlated with adenoma numbers.

\section{Conclusions}

If the findings of this study can be independently verified, FAP-MCR positive patients harboring wildtype polymorphism for rs 1984112 may have a 5-10 year earlier onset of polyposis and additional disease risk then heterozygotes and homozygotes. This finding could have a risk stratifying effect on the treatment of disease in MCR affected individuals and enhance our understanding of the disease process's potential modifier.

\section{Abbreviations \\ AFAP: Attenuated familial adenomatous polyposis; APC: Adenomatous polyposis coli; CD36: Cluster of differentiation 36; CRC: Colorectal cancer; FAP: Familial adenomatous polyposis; MCR: Mutation cluster region; Min: Mouse intestinal neoplasia; Mom: Modifier of min; SNPs: Single nucleotide polymorphisms}

\section{Authors' contributions}

TC carried out the molecular genetic studies, $C O$ and MC provided statistical analysis guidance, AP, PGP participated in the study design, El, TB, MM, MH and $A Z$ were involved in the APC variant detection. RJS participated in the 
design of the study and coordination, of the statistical analysis, interpretation and drafted the manuscript. All authors read and approved the final manuscript.

\section{Funding}

This work was supported in part by the Cancer Institute NSW, Australia and the University of Newcastle, NSW, Australia.

\section{Availability of data and materials}

All data generated or analysed during this study are included in this published article.

\section{Declarations}

\section{Ethics approval and consent to participate}

All patients consented for the use of their de-identified DNA to be used in future research into their condition. The study was approved by the Hunter New England Human Research Ethics Committee and Human Research Ethics Committee of the University of Newcastle, Newcastle, Australia.

\section{Consent for publication}

Not applicable.

\section{Competing interests}

The authors declare that they have no competing interests.

\section{Author details}

${ }^{1}$ School of Biomedical Sciences, Faculty of Health, University of Newcastle, Callaghan Campus, NSW 2308 Newcastle, Australia. ²Division of Molecular Medicine, NSW Health Pathology North, 2305 New Lambton, NSW, Australia. ${ }^{3}$ Centre for Clinical Epidemiology and Biostatistics, University of Newcastle, Newcastle, NSW, Australia. ${ }^{4}$ Department of Surgery, John Hunter Hospital, Newcastle, Australia. ${ }^{5}$ Department of General, Endocrinological Surgery and Gastroenterological Oncology, Poznan University of Medical Sciences, Poznan, Poland. ${ }^{6}$ Institute of Human Genetics, Polish Academy of Sciences, Poznan, Poland. ${ }^{7}$ Hunter Medical Research Institute, John Hunter Hospital, 2305 New Lambton, NSW, Australia.

\section{Received: 14 March 2021 Accepted: 20 April 2021}

\section{Published online: 29 April 2021}

\section{References}

1. Henrikson NB, Webber EM, Goddard KA, Scrol A, Piper M, Williams MS, Zallen DT, Calonge N, Ganiats TG, Janssens AC, Zauber A, Lansdorp-Vogelaar I, van Ballegooijen M, Whitlock EP. Family history and the natural history of colorectal cancer: systematic review. Genet Med. 2015;17:702-12.

2. Bülow S, Faurschou T, Nielsen T, Bülow C, Bisgaard ML, Karlsen L, Moesgaard F. (1996) The Incidence Rate of Familial Adenomatous Polyposis. Results From the Danish Polyposis Register J Colorectal Dis. 1996;11(2):8891.

3. Bisgaard ML, Fenger K, Bulow S, et al. Familial adenomatous polyposis (FAP): frequency, penetrance, and mutation rate. Hum Mutat. 1994;3:121-5.

4. Decosse JJ, Adams MB, Condon RE. Familial polyposis. Cancer. 1977;39:26773.

5. McKusick VA. Genetics and large-bowel cancer. Am J Digest Diseases. 1974; 19:954-8.

6. Syngal S, Brand RE, Church JM, Giardiello FM, Hampel HL, Burt RW. American College of Gastroenterology. ACG clinical guideline: genetic testing and management of hereditary gastrointestinal cancer syndromes. Am J Gastroenterol. 2015 Feb;110(2):223-62.

7. van der Luijt RB, Vasen HF, Tops CM, Breukel C, Fodde R, Meera Khan P. APC mutation in the alternatively spliced region of exon 9 associated with late onset familial adenomatous polyposis. Hum Genet. 1995 Dec;96(6):705-10.

8. Hernegger GS, Moore HG, Guillem JG. Attenuated familial adenomatous polyposis: an evolving and poorly understood entity. Dis Colon Rectum. 2002 Jan;45(1):127-34

9. Dobbie Z, Spycher M, Hurliman R, Ammann R, Ammann T, Roth J, Muller A, Muller $\mathrm{H}$, Scott RJ. Mutational analysis of the first 14 exons of the adenomatous polyposis coli (APC) gene. Eur J Cancer. 1994;30A:1709-13.
10. Scott RJ, Froggatt NJ, Trembath RC, Evans GR, Hodgson SV, Maher ER. Familial infiltrative fibromatosis (desmoid tumours) (MIM135290) caused by a recurrent 3' APC gene mutation. Hum Mol Genet. 1996;5:1921-4.

11. Eccles DM, van der Luijt $R$, Breukel C, Bullman $H$, Bunyan D, Fisher A, Barber J, du Boulay C, Primrose J, Burn J, Fodde R. Hereditary Desmoid Disease Due to a Frameshift Mutation at Codon 1924 of the APC Gene. Am J Hum Genet. 1996;59(6):1193-201.

12. Fearnhead NS, Britton MP, Bodmer WF. The ABC of APC. Hum Mol Genet. 2001;10(7):721-33.

13. Nieuwenhuis MH, Vasen HFA. Correlations between mutation site in APC and phenotype of familial adenomatous polypsis (FAP):A review of the literature. Crit Rev Oncol Hematol. 2007;61:153-61.

14. Miyoshi Y, Nagase H, Ando H, Horii A, Ichii S, Nakatsuru S, Aoki T, Miki Y, Mori T, Nakamura Y. Somatic mutations of the APC gene in colorectal tumors mutation cluster region in the APC gene. Hum Mol Genet. 1992;1: 229-33

15. Sieber OM, Segditsas S, Knudsen AL, Zhang J, Luz J, Rowan AJ, Spain SL, Thirlwell C, Howarth KM, Jaeger EE, Robinson J, Volikos E, Silver A, Kelly G, Aretz S, Frayling I, Hutter P, Dunlop M, Guenther T, Neale K, Phillips R, Heinimann K, Tomlinson IP. Disease severity and genetic pathways in attenuated familial adenomatous polyposis vary greatly but depend on the site of the germline mutation. Gut. 2006;55:1440-8.

16. Cormier RT, Hong KH, Halberg RB, Hawkins TL, Richardson P, et al. Secretory phospholipase Pla2g2a confers resistance to intestinal tumorigenesis. Nat Genet. 1997;17:88-91.

17. Silverman KA, Koratkar R, Siracusa LD, Buchberg AM. Identification of the modifier of Min 2 (Mom2) locus, a new mutation that influences Apcinduced intestinal neoplasia. Genome Res. 2002;12:88-97.

18. Dietrich WF, Lander ES, Smith JS, Moser AR, Gould KA, et al. Genetic identification of Mom-1, a major modifier locus affecting Min-induced intestinal neoplasia in the mouse. Cell. 1993;75:631-9.

19. Haines J, Johnson V, Pack K, Suraweera N, Slijepcevic P, et al., 2005. Genetic basis of variation in adenoma multiplicity in $\mathrm{ApC}^{\mathrm{Min} /+} \mathrm{Mom}^{\mathrm{S}}$ mice. Proc. Natl. Acad. Sci. USA 102 2868-2873.

20. Kwong LN, Shedlovsky A, Biehl BS, Clipson L, Pasch CA, Dove WF. Identification of Mom7, a novel modifier of ApcMin/+ on mouse chromosome 18. Genetics. 2007;176:1237-44.

21. Dobbie Z, Muller H, Scott RJ. Secretory phospholipase A2 does not appear to be associated with phenotypic variation in FAP. Hum Genet. 1996;98:386-90.

22. Seiber OM, Tomlinson IP, Lamlum H. The adenomatous polyposis coli (APCI) tumour suppressor - genetics, function and disease. Mol Med Today. 2000; 6(12):462-9.

23. Plasilova $M$, Russell $A$, Wanner $A$, et al. Exclusion of an extracolonic disease modifier locus on chromosome 1p33-36 in a large Swiss familial adenomatous polyposis kindred. Eur J Hum Genet. 2004;12:365-71. https:// doi.org/10.1038/sj.ejhg.5201157.

24. Otterpohl KL, Gould KA. Genetic dissection of the Mom5 modifier locus and evaluation of Mom5 candidate genes. Mamm Genome. 2015;26:235-47.

25. Holmes M, Connor T, Oldmeadow C, Pockney PG, Scott RJ, Talseth-Palmer BA. (2018) CD36 - a plausible modifier of disease phenotype in familial adenomatous polyposis. Hered Cancer Clin Pract 16:14 https://doi.org/10.11 86/s1305-018-0096-y.

26. Ma X, Bacci S, Mlynarski W, Gottardo L, Soccio T, Menzaghi C, et al. A common haplotype at the CD36 locus is associated with high free fatty acid levels and increased cardiovascular risk in Caucasians. Hum Mol Genet. 2004;13(19):2197-205.

27. Love-Gregory L, Sherva R, Schappe T, Qi JS, McCrea J, Klein S, et al. Common CD36 SNPs reduce protein expression and may contribute to a protective atherogenic profile. Hum Mol Genet. 2011;20(1):193201.

28. Bokor S, Legry V, Meirhaeghe A, Ruiz JR, Mauro B, Widhalm K, et al. Singlenucleotide polymorphism of CD36 locus and obesity in European adolescents. Obesity (Silver Spring). 2010;18(7):1398-403.

29. Albuquerque C, Breukel C, van der Luijt R, Fidalgo P, Lage P, Slors FJM, Leitão CN, Fodde R, Smits R. (2002) The 'just-right' signaling model: APC somatic mutations are selected based on a specific level of activation of the $\beta$-catenin signaling cascade Human Molecular Genetics, Volume 11, Issue 13, 15 June 2002, Pages 1549-1560.

30. Crabtree M, Sieber OM, Lipton L, Hodgson SV, Lamlum H, Thomas HJW, Neale K, Phillips RKS, Heinimann K, Tomlinson IPM. Refining the relation between "first hits" and "second hits" at the APC locus: The "loose fit" model 
and evidence for differences in somatic mutation spectra among patients. Oncogene. 2003;22(27):4257-65.

31. Scott RJ, Meldrum C, Crooks R, Spigelman AD, Kirk J, Tucker K, Koorey D, Hunter Family Cancer Service. Familial adenomatous polyposis: more evidence for disease diversity and genetic heterogeneity. Gut. 2001;48(4): 508-14.

32. Scott RJ, Taeschner W, Heinimann K, Mueller H, Dobbie Z, Morgenthaler S, Hoffmann F, Peterli B, Meyer UA. Association of extracolonic manifestations of familial adenomatous polyposis with acetylation phenotype in a large FAP kindred. Eur J Hum Genet. 1997;5(1):434-49.

33. Crabtree MD, Fletcher C, Churchman M, Hodgson SV, Neale K, Phillips RK, Tomlinson IP. Analysis of candidate modifier loci for the severity of colonic familial adenomatous polyposis with evidence for the importance of the $\mathrm{N}$ acetyl transferases. Gut. 2004;53(2):271-6.

34. Rodrigues AC, Sobrino B, Genvigir FDV, Willrich MAV, Arazi SS, Dorea EL, Bernik MMS, Bertolami M, Faludi AA, Brion MJ, Carracedo A, Hirata MH, Hirata RDC. Genetic variants in genes related to lipid metabolism and atherosclerosis, dyslipidemia and atorvastin response. Clin Chim Acta. 2013; 417:8-11.

35. Herbey I, Ivankova NV, Katkoori VR, Mamaeva OA. Colorectal cancer and hypercholesterolemia: Review of current research. Exp Oncol. 2005;27:166-78.

\section{Publisher's Note}

Springer Nature remains neutral with regard to jurisdictional claims in published maps and institutional affiliations.

Ready to submit your research? Choose BMC and benefit from:

- fast, convenient online submission

- thorough peer review by experienced researchers in your field

- rapid publication on acceptance

- support for research data, including large and complex data types

- gold Open Access which fosters wider collaboration and increased citations

- maximum visibility for your research: over $100 \mathrm{M}$ website views per year

At $\mathrm{BMC}$, research is always in progress.

Learn more biomedcentral.com/submissions 